\title{
O Papel da Oferta e da Demanda por Qualificação na Evolução do Diferencial de Salários por Nível Educacional no Brasil
}

\author{
Alexandre Reggi Pecora \\ Mestre em Economia (FEA/USP e Analista de Pesquisa do Itaú-Unibanco) \\ Endereço: Av. Dr. Hugo Beolchi, 900 - piso -1, Torre Eudoro Villela, São Paulo - SP - Brasil \\ CEP: 04310-030 - E-mail: alexandre.pecora@usp.br
}

\author{
Naercio Menezes-Filho \\ Professor - (Insper e FEAVUSP) \\ Endereço: R. Quatá, 300 - Vila Olímpia, São Paulo - SP - Brasil \\ CEP: 04546-042 - E-mail: naercioamf@insper.edu.br
}

Recebido em 09 de abril de 2013. Aceito em 13 de dezembro de 2013.

\section{Resumo}

Este artigo tem como objetivo analisar o impacto da oferta e da demanda por trabalho qualificado sobre o diferencial de salários entre trabalhadores de elevada e baixa qualificação para o Brasil, durante o período de 1992 a 2009. Para tanto, foi utilizado um modelo microeconômico de oferta e demanda por trabalho qualificado, em que o grupo de baixa qualificação é formado por uma combinação CES entre o grupo intermediário e não qualificado. Os resultados apontam para uma elevação do diferencial de salários entre o trabalho de elevada qualificação (com ensino superior) e baixa qualificação (com ensino médio ou ensino básico) no período de 1992 a 2001, impulsionada pelo aumento da demanda por trabalho qualificado. Porém, no período de 2002 a 2009 , houve uma pequena diminuição desse diferencial, determinada pela intensificação da oferta relativa de trabalho qualificado que ocorreu durante esse período.

\section{Palavras-Chave}

salários, educação, oferta, demanda, desigualdade salarial

\begin{abstract}
The aim of this paper is to assess the impact of supply and demand for skills in the wage differentials between skilled and unskilled workers in Brazil, during 1992 and 2009. To do so, a microeconomic model of supply and demand for skill was used where a worker's skill is directly linked with its educational level. A rise in the skill premium (wage differentials between college and less than college workers) was observed between 1992 and 2001, driven by the demand for skilled labor. Between 2002 and 2009, a slight decrease in the skill premium was observed, which was driven by the intensification of the relative supply of skilled workers.
\end{abstract}

\section{Keywords}

skill premium, supply, demand

\section{JEL Classification}

J23, J24, O15 


\section{Introdução}

Nos países desenvolvidos, o prêmio por qualificação - geralmente identificado como a razão entre o salário médio de indivíduos com ensino superior completo e o salário médio de indivíduos com segundo grau completo - é um tema bastante abordado em diversos estudos. Nesses países houve um aumento desproporcional, principalmente a partir década de 1980, nos salários relativos do grupo de indivíduos que detém o ensino superior completo, quando comparados aos salários de indivíduos com educação que se estende apenas ao ensino médio completo. Apesar de ainda existirem controvérsias sobre a exatidão desse movimento nos salários (ver Atkinson, Piketty e Saez, 2011), o prêmio por qualificação é um fato bem documentado na literatura desses países. Muitos trabalhos, como os de Katz e Murphy (1992), Autor, Katz e Krueger (1998), Autor, Katz e Kearney (2006), e Carneiro and Lee (2009) mostram que o avanço tecnológico foi o grande fator que estimulou a demanda por profissionais qualificados e assim impulsionou o prêmio por qualificação. ${ }^{1}$

Entretanto, existem poucas investigações acerca da evolução recente do prêmio por qualificação em países menos desenvolvidos. Mais especificamente, pouco se sabe nesses países sobre a evolução desse prêmio e como ele é influenciado pela oferta e a demanda por trabalhadores de diferentes habilidades. Por diversas razões, o entendimento dos determinantes dos salários relativos é importante nesses países, principalmente pelo fato da elevada desigualdade de renda predominante neles (ver Manacorda, Sanchez-Paramo e Schady, 2010). Nesse sentido, é importante ressaltar que políticas direcionadas à redução da desigualdade de renda podem ser ineficientes caso não haja um entendimento de como os movimentos nos salários são determinados por mudanças na demanda relativa por trabalho qualificado e/ou mudanças na oferta relativa de trabalhadores de diferentes níveis de educação.

Por exemplo, conforme Manacorda, Sanchez-Paramo e Schady (2010), caso a mudança nos salários de alguma região seja determinada principalmente por restrições no lado da oferta de pessoas qualificadas, medidas que facilitem o acesso ou a qualidade de ensino podem ajustar os diferenciais de salários. Por outro lado, caso os

1 A análise do diferencial de salários entre esses dois grupos de educação é muito comum na literatura tradicional. Para uma revisão detalhada da literatura internacional a respeito do diferencial de salários por educação ver Acemoglu e Autor (2010). 
salários estejam sofrendo influência da demanda por trabalhadores de determinada qualificação, políticas que afetem o lado da procura por trabalho seriam mais apropriadas, como o investimento em tecnologia ou o estímulo ao comércio internacional.

A distribuição de salários no mercado de trabalho brasileiro teve uma importante influência na redução da desigualdade de renda observada na última década (em 2001, o coeficiente de Gini era de 0,596 e passou para 0,543 em 2009, apresentando redução em todos os anos desse período). Essa importância pode ser verificada no Gráfico 1. O gráfico expõe a variação do índice de Gini que mede a desigualdade de renda per capita e de salários, tomando 1995 como ano de referência. É evidenciado que, principalmente a partir do ano 2000, uma grande redução na desigualdade de salários direcionou a queda recente na desigualdade de renda brasileira. ${ }^{2}$ Motivado pela variação recente observada na distribuição de salários, o objetivo desta pesquisa é compreender o diferencial de salários relativos entre diferentes grupos de educação e idade, através do papel da oferta e da demanda de trabalho.

Certamente existem outros fatores, além da educação, que impactam na renda de um indivíduo como, por exemplo, efeitos não observáveis que definem a qualidade de um trabalhador. Outras questões relacionadas ao mercado de trabalho brasileiro e que também influenciam a desigualdade de renda são a segmentação (ver Cacciamali, 1991), discriminação (Henriques, 2001), inflação (Camargo e Neri, 1999 e Hoffman, 1995) e ciclos econômicos (Bonelli e Ramos, 1995). Neste trabalho não tratamos de efeitos não observáveis dos indivíduos, ${ }^{3}$ tampouco de questões particulares do mercado de trabalho brasileiro, de modo que o nosso foco exclusivo é a diferença nos níveis de educação entre os trabalhadores.

Este artigo segue a metodologia de Manacorda, Sanchez-Paramo e Schady (2010). Segundo a metodologia dos autores, são calculadas elasticidades de substituição entre trabalhadores de diferentes qualidades, bem como uma demanda linear direcionada ao trabalho qualificado. Os autores calculam elasticidades de substituição conjunta-

2 No Brasil os salários são um componente muito representativo da renda dos indivíduos, eles correspondem a quase $80 \%$ do total da renda de um brasileiro (Barros, Foguel e Ulyssea, 2006)

3 Embora existam indícios de uma correlação entre educação e alguns efeitos não observáveis como criatividade e persistência, ver Lam e Schoemi (1973). 
mente para cinco países latino-americanos (Argentina, Brasil, Chile, Colômbia e México) durante as décadas de 1980 e 1990. Entretanto, neste trabalho isolamos as elasticidades apenas para o Brasil. Além disso, consideramos tanto homens quanto mulheres em nossa análise, sendo que os autores apenas consideraram o sexo masculino. Também trabalhamos com um período mais recente de observação dos dados: 1992 a 2009. Entendemos que uma nova análise acerca do papel da oferta e da demanda por habilidade se faz necessária no Brasil devido principalmente à recente elevação observada para os salários relativos de indivíduos de baixo nível educacional.

Vários artigos examinaram a questão de desigualdade no Brasil, e em particular o comportamento dos diferenciais de salários por educação. ${ }^{4}$ Em um artigo recente, Fernandes e Menezes-Filho (2012) também analisam o papel da demanda na evolução dos diferenciais de salários no Brasil, usando três grupos educacionais. Porém, o enfoque dos autores é diferente do nosso, pois naquele artigo os trabalhadores de nível intermediário podem ser alocados em tarefas simples e complexas. Os resultados mostram que houve um aumento na demanda relativa por trabalhadores qualificados nas tarefas complexas e por trabalhadores intermediários nas tarefas simples. Este artigo utiliza uma abordagem alternativa, em que a substitutibilidade entre os grupos etários e entre os trabalhadores não qualificados ganha destaque.

Este artigo está estruturado da seguinte maneira: na seção 2 explicamos a nossa base de dados e entramos com mais detalhes acerca da evolução recente dos salários relativos no Brasil e dos movimentos na oferta de trabalho de diferentes qualificações. Na seção 3, apresentamos o modelo teórico e a metodologia utilizada e interpretamos os resultados encontrados para as elasticidades de substituição entre os grupos etários e os grupos de qualificação. Finalmente, na seção 4, concluímos os resultados encontrados e propomos futuras pesquisas.

\section{Análise de Dados}

A fonte de dados para as análises aqui expostas, e também para as estimações mais adiante, advém dos microdados da PNAD (Pesquisa Nacional por Amostra de Domicílios) contemplados entre os anos de

4 Ver Gonzaga et al. (2005), por exemplo. 
1992 e 2009. A partir das informações das PNADs construímos duas medidas, uma para os salários e outra para a oferta de mão de obra.

Para a amostra de salários seguimos a literatura tradicional (ver Card e Lemieux, 2001) e consideramos apenas os indivíduos com ensino básico completo (equivalente a quatro anos de estudo, que chamaremos doravante de não qualificados), ensino médio completo (onze anos de estudo, que chamaremos doravante de intermediários), com ensino superior completo (quinze anos de estudo, que chamaremos doravante de qualificados), que pertencem à PEA e responderam a pergunta sobre o valor de seu salário. Construímos então o salário de um grupo de qualificação, ano a ano, como a média de salários de todos os indivíduos pertencentes ao grupo, sendo que cada salário é normalizado pelas horas semanais de trabalho. Apenas consideramos os indivíduos jornada de trabalho maior ou igual a vinte horas semanais. Todos os salários anuais também são corrigidos a cada ano pelo IPCA (Índice Nacional de Preços ao Consumidor Amplo).

Quanto à oferta de trabalho, esta corresponde às horas semanais de trabalho de todos os indivíduos pertencentes a um dos três níveis de ensino de referência. Para aqueles indivíduos que possuem algum grau de instrução incompleto é feita uma divisão na contabilização de sua oferta. As horas de oferta desse indivíduo são ponderadas pela distância entre o seu salário e os salários médios dos níveis de ensino de referência.

Tendo definido os três grupos de qualificação de nosso interesse e as medidas de oferta e de salários, apresentamos na sequência as principais tendências referentes aos salários e à oferta de mão de obra no mercado de trabalho.

\subsection{O Diferencial de Salários e de Oferta de Trabalhadores}

No caso americano, é bastante comum rotular um indivíduo com graduação completa como qualificado e aqueles apenas com ensino médio como não qualificado. Essa categorização é justificável porque é razoável afirmar que, em termos gerais, a força de trabalho americana encontra-se segmentada nesses dois grupos. Porém, no caso brasileiro, a situação é diferente; a força de trabalho é bastante 
heterogênea em termos de nível educacional. Para contornar isso, consideramos os três grupos de qualificação já mencionados acima, ao invés de apenas dois.

Na Tabela 1, exploramos como se comportou a evolução dos retornos para esses três níveis de educação frente à variação em quatro medidas de oferta: população geral, população economicamente ativa (PEA), empregados e horas totais de trabalho. Para calcular os retornos para os níveis de educação regredimos $(\log )$ salários sobre idade, idade ao quadrado, dummies referentes aos níveis de educação intermediário e qualificado, e dummies de ano. Os coeficientes para as duas dummies de educação estão expostas nas primeiras duas linhas da tabela. As demais linhas mostram as médias anuais da distribuição da população, da PEA, dos empregados e das horas trabalhadas, entre os três grupos de qualificação.

O padrão exposto pela Tabela 1 é claro: houve uma mudança expressiva na composição dos três grupos de qualificação durante o período considerado. O grupo intermediário aumentou a sua proporção na oferta de trabalho total em torno de $25 \%$; essa elevação foi semelhante em todas as medidas de oferta consideradas. Verificando o retorno para a educação, vemos que ele aumentou sensivelmente para os qualificados em relação aos intermediários de 1992 a 2001, e após esse ano não sofreu uma alteração expressiva. Já considerando o retorno que os intermediários comandam em relação aos não qualificados, vemos que ele sofreu um tímido aumento de 1992 a 2001, mas depois caiu sensivelmente até 2009. Esses dados indicam que o grupo não qualificado foi o grande favorecido em termos de salários relativos durante a última década.

\section{Metodologia}

Este artigo segue uma metodologia clássica em que a oferta de trabalho é exógena e que a demanda por trabalho qualificado, por hipótese, possui um padrão de crescimento linear ao longo do tempo. Com essas hipóteses, podemos estimar as elasticidades de substituição entre os grupos de trabalho considerados aqui (não qualificado, intermediário, qualificado), bem como a tendência linear de crescimento da demanda por trabalho qualificado. 
Assim, esperamos concluir se o principal determinante da mudança no diferencial de salários está relacionado aos deslocamentos na oferta relativa entre os grupos de educação que ocorreram durante as duas últimas décadas. Numa última etapa, relaxamos a hipótese do crescimento linear da demanda e estimamos uma forma funcional em que a demanda possui um crescimento quadrático.

As elasticidades de substituição entre os trabalhadores têm um papel importante no impacto da oferta sobre o diferencial de salários. Para compreender isso, podemos pensar no caso em que dois tipos de trabalho sejam substitutos perfeitos (ou seja, a elasticidade de substituição entre eles é extremamente elevada); nesse caso, mudanças na oferta direcionadas a qualquer um desses dois tipos de trabalho não alterarão em nada o diferencial de salários entre eles, uma vez que a produção da economia pode usar da mesma forma qualquer tipo de trabalho. Por outro lado, se a elasticidade de substituição entre dois tipos de trabalho é baixa, a oferta relativa terá um grande impacto na determinação da razão de salários entre os tipos de trabalho. Portanto, quanto menor a elasticidade de substituição entre os grupos de trabalho, maior será o efeito da oferta relativa de algum desses grupos na determinação do diferencial de salários entre eles.

\subsection{Modelo Teórico}

O modelo é construído assumindo as hipóteses de que a demanda é função da produtividade marginal do trabalho, a oferta é exógena, e os salários são determinados pela interação entre a demanda e a oferta de trabalho. A produção da economia é representada por meio de uma função CES e utiliza dois insumos agregados de trabalho, com dois níveis distintos de qualificação: alta e baixa. Para a simplicidade do modelo o capital não é considerado. Temos então a seguinte função de produção:

$$
Y_{t}=A_{t}\left(N_{U t}^{\rho}+\alpha_{t} N_{S t}^{\rho}\right)^{1 / \rho}
$$

Onde Y é o produto total, A é uma mudança tecnológica que aumenta a produtividade dos fatores, $\mathrm{N}$ é o nível de emprego (ou oferta de trabalho), U denota o grupo não qualificado e $\mathrm{S}$ denota o grupo qua- 
lificado, t é o tempo e $\rho$ é uma função da elasticidade de substituição entre os dois grupos de qualidade de trabalho. Essa elasticidade de substituição é definida por $\sigma_{E}=\frac{1}{1-\rho}$. O parâmetro $\alpha_{t}$ é uma medida da produtividade relativa dos trabalhadores qualificados no período $t$.

Para construir a oferta de trabalho agregada para cada grupo de educação (identificadas na Equação 5 como $N_{U t}$ e $N_{S t}$ ), faz-se uma soma de todos os trabalhadores pertencentes a diferentes grupos idades, identificados como $a$ (lembramos que consideramos aqui seis grupos, a $=6$ ), ponderando pela produtividade de cada grupo etário:

$$
N_{j t}=\left(\sum_{a} \beta_{j a} N_{j a t}^{\delta}\right)^{1 / \delta} \quad j=S, U
$$

Onde $\delta$ é uma função da elasticidade de substituição entre diferentes grupos de idade. Nós assumimos que essa elasticidade de substituição, definida por $\sigma_{A}$, tal que $\sigma_{A}=\frac{1}{1-\gamma}$, é a mesma entre os grupos de educação. Finalmente, $\beta_{j a}$ é uma medida da produtividade relativa do grupo de idade $\alpha$, pertencente ao nível de qualificação $j$. Assumimos que $\beta_{j a}$ é invariante no tempo, eliminando qualquer efeito de mudanças na demanda por trabalhadores de diferentes experiências.

Adicionalmente, é assumido que o grupo de baixa qualificação $(U)$ constitui uma combinação CES entre dois grupos de educação: intermediário e não qualificados. Esses grupos representam, respectivamente, indivíduos com ensino médio completo e indivíduos apenas com ensino básico completo (eles serão identificados nas equações abaixo por 2 e 1 , respectivamente). O grupo de alta qualificação $(H)$ contempla os trabalhadores com nível superior completo de educação (identificados por 3 , de modo que $\mathrm{H} \equiv 3$ ). Isso implica:

$$
N_{U a t}=\left(\delta_{a} N_{1 a t}^{\gamma}+N_{2 a t}^{\gamma}\right)^{1 / \gamma}
$$

Onde $\delta_{\alpha}$ é uma medida da produtividade relativa dos trabalhadores não qualificados em relação aos intermediários, e $\gamma$ é uma função da elasticidade de substituição entre esses dois grupos $\left(\sigma_{U}\right)$, de modo que $\sigma_{A}=\frac{1}{1-\gamma}$. 
Sob a hipótese de que os mercados de trabalho e de produção são perfeitamente competitivos, podemos manipular (1) a (3) para derivar expressões para os salários $(W)$ de indivíduos de experiência j e educação e no período t:

$$
\begin{aligned}
& w_{3 a t}=X_{t}+\ln \alpha_{t}+\ln \beta_{3 a}-\frac{1}{\sigma_{E}} n_{3 t}-\frac{1}{\sigma_{A}}\left(n_{3 a t}-n_{3 t}\right) \\
& w_{2 a t}=X_{t}+\ln \beta_{U a}-\frac{1}{\sigma_{E}} n_{U t}-\frac{1}{\sigma_{A}}\left(n_{U a t}-n_{U t}\right)-\left(\frac{1}{\sigma_{U}} n_{2 a t}-n_{U a t}\right) \\
& w_{1 a t}=X_{t}+\ln \beta_{U a}+\ln \delta_{a}-\frac{1}{\sigma_{E}} n_{U t}-\frac{1}{\sigma_{A}}\left(n_{U a t}-n_{U t}\right)-\frac{1}{\sigma_{U}}\left(n_{1 a t}-n_{U a t}\right)
\end{aligned}
$$

Onde $X_{t}=\rho \ln \left(A_{t}\right)+(1-\rho) \ln \left(Y_{t}\right), n=\ln N, w=\ln W$

As Equações (4) a (6) constituem a base da análise empírica. Elas ilustram que os (log) salários são uma função da produtividade total de fatores, representados por $X_{t}$, shifts de demanda (em $\alpha$ s e $\beta$ s), e uma série de termos de oferta de trabalho.

O primeiro termo de oferta captura o efeito de mudanças na oferta de um dado grupo de qualificação, $n_{U t}$ e $n_{3 t}=n_{H t}$. O coeficiente nesses termos é uma transformação da elasticidade de substituição entre o trabalho de qualificação baixa (U) e alta (S): $\sigma_{E}$. O segundo termo de oferta, que aparece em (5) e (6), representa mudanças na composição da oferta de trabalho de baixa qualidade (U), isso é, mudanças na proporção de trabalhadores intermediários e não qualificados dentro do grupo de trabalho de qualificação baixa: $\left(n_{\text {eat }}-n_{\text {Uat }}\right)$ onde e $=1,2$. O coeficiente nesse termo é uma transformação da elasticidade de substituição entre trabalhadores terciários e secundários, $\sigma_{H}$. Finalmente, o terceiro termo de oferta captura mudanças na composição de experiência de cada grupo de educação: $n_{e j t}-n_{j t}$ onde e $=1,2,3$ e $\mathrm{j}=\mathrm{S}, \mathrm{U}$. O coeficiente nesse termo é uma transformação da elasticidade de substituição entre trabalhadores de diferentes experiências dentre cada grupo de educação, $\sigma_{A}$.

As Equações (4) a (6) não podem ser estimadas diretamente, pois os termos de oferta agregada $n_{S t}$ e $n_{U t}$ não são conhecidos. Para isso, é necessário realizar um procedimento de estimação em etapas de 
modo a identificar cada termo das Equações (4) a (6), para depois poder estimar os coeficientes. Esse procedimento está detalhado na estratégia empírica logo abaixo.

\subsection{Estratégia Empírica}

O objetivo central da estratégia empírica proposta é obter estimativas dos três coeficientes que definirão as elasticidades de substituição $\left(\frac{1}{\sigma_{E}}\right),\left(\frac{1}{\sigma_{U}}\right)$ e $\left(\frac{1}{\sigma_{A}}\right)$, bem como uma estimativa para $\alpha_{t}$. Este último termo captura as diferenças na produtividade relativa, e, portanto, na demanda relativa, entre trabalho de qualificação alta e baixa. Assume-se que $\alpha_{t}$ tem um padrão de crescimento constante ao longo do tempo, de modo que ele é expresso por uma tendência linear na forma funcional do modelo.

Para poder identificar todos os parâmetros devem-se realizar três etapas de estimação, conforme a estratégia proposta por Card e Lemieux (2001), seguida também por Manacorda, Sanchez-Paramo e Schady (2010).

Etapa 1: produz estimativas da elasticidade de substituição entre os grupos de qualificação baixa (intermediários e não qualificados): $\sigma_{U}$, e também da eficiência dos trabalhadores não qualificados em relação aos intermediários $\gamma_{\alpha}$, que podem ser usados para construir $N_{\text {Uat. Subtraindo }} w_{2 a t}$ de $w_{1 a t}$ usando (5) e (6) pode-se obter:

$$
w_{2 a t}-w_{1 a t}=d_{a}-\frac{1}{\sigma_{U}}\left(n_{2 a t}-n_{1 a t}\right)
$$

Onde $d_{\alpha}$ são dummies referentes aos grupos etários, que representam a log produtividade de trabalhadores não qualificados em relação aos intermediários. Na prática, o diferencial de salários entre esses dois tipos de trabalhadores são regredidos sobre a oferta relativa de trabalho não qualificado mais as dummies de grupo de idade. Com isso, obtemos estimativas de $\gamma_{\alpha}$ e $\sigma_{U}$. Completamos assim a etapa 1 utilizando essas estimativas em (3) para computar $N_{\text {Uat }}$. 
Etapa 2: produz estimativas da elasticidade de substituição entre os grupos de experiência, $\sigma_{A}$, e de todas as medidas de produtividade específicas de experiência, $\beta_{j}$, que podem ser usadas para construir $N_{j t}(\mathrm{j}=\mathrm{S}, \mathrm{U})$ em seguida. A partir de (4) a (6) e com algumas manipulações, obtemos:

$\left(w_{3 a t}-w_{e a t}\right)=d_{t}+d_{e a}-1 / \sigma_{A}\left(n_{3 a t}-n_{U a t}\right)-1 / \sigma_{U}\left(n_{U a t}-n_{\text {eat }}\right) \mathrm{e}=1,2$

Onde $d_{e \alpha}$ são dummies que representam efeitos de idade-educação e $d_{t}$ são dummies que representam efeitos do ano. Em particular, $d_{2 a}=\ln \beta_{U a}-\ln \beta_{3 a}, d_{t}=\ln \alpha_{t}-\left(\frac{1}{\sigma_{E}}-\frac{1}{\sigma_{A}}\right)\left(n_{U t}-n_{3 t}\right)$. Esse exercício produz uma estimativa para $\sigma_{A}$ o qual plugamos em (4) a (6) para obter:

$$
\begin{aligned}
& w_{3 a t}+\frac{1}{\sigma_{A}} n_{3 a t}=d_{3 t}+\ln \beta_{3 a} \\
& w_{2 a t}+\frac{1}{\sigma_{A}} n_{U a t}+\frac{1}{\sigma_{U}}\left(n_{2 a t}-n_{U a t}\right)=d_{U t}+\ln \beta_{U a} \\
& w_{1 a t}+\frac{1}{\sigma_{A}} n_{U a t}+\frac{1}{\sigma_{U}}\left(n_{1 a t}-n_{U a t}\right)=d_{U t}+\ln \beta_{U a}
\end{aligned}
$$

Onde o lado esquerdo das equações representam (log) salários corrigidos pela oferta, $d_{3 t}=X_{t}+\ln \alpha_{t}-\left(\frac{1}{\sigma_{E}}-\frac{1}{\sigma_{A}}\right) n_{3 t} d_{U t}=X_{t}-\left(\frac{1}{\sigma_{E}}-\frac{1}{\sigma_{A}}\right) n_{U t}$. $\mathrm{Na}$ prática, regredimos os (log) salários em dummies de qualificação interagidas com dummies de idade para produzir os efeitos de idade esperados $\beta$. Por fim, essa etapa é concluída plugando essas estimativas junto com $\sigma_{A}$ de volta em (2) para construir $N_{S t}$ e $N_{U t}$.

Etapa 3: A terceira e final etapa produz uma estimativa da elasticidade de substituição entre o trabalho de qualidade alta e trabalho de qualidade baixa: $\sigma_{E}$. De (4) a (6) e assumindo que a demanda relativa segue uma tendência linear ao longo do tempo (i.e. $\ln \alpha_{t}=f_{0}+f_{1} t$ ), obtemos:

$$
\begin{gathered}
w_{3 a t}-w_{e a t}=f_{0}^{\prime}-f_{1} t+d_{e a} \\
-1 / \sigma_{E}\left(n_{3 t}-n_{U t}\right)-1 / \sigma_{A}\left[\left(n_{U t}-n_{U a t}\right)-\left(n_{3 t}-n_{3 a t}\right)\right]-1 / \sigma_{u}\left(n_{U a t}-n_{e a t}\right) \\
\mathrm{e}=1,2
\end{gathered}
$$


O lado esquerdo da equação representa diferenciais de (log) salários entre trabalhadores não qualificados + intermediários (grupo de qualificação baixa) e trabalhadores qualificados (grupo de qualificação alta). O coeficiente $f_{1}$ captura mudanças no lado da demanda, favorecendo o trabalho qualificado. $\mathrm{O}$ coeficiente do primeiro termo de oferta fornece uma estimativa de $\sigma_{E}$. Os coeficientes dos demais termos de oferta fornecem novas estimativas de $\sigma_{A}$ e $\sigma_{U} \mathrm{Na}$ última etapa deste trabalho, na seção 3.4, estimamos a Equação (12) adicionando um termo quadrático $-f_{1} t^{2}-$ e analisamos os novos resultados.

\subsection{Resultados}

Antes de analisar os resultados devemos descrever como construímos os salários e a oferta dos três grupos de trabalhadores considerados. Consideramos o seguinte critério para construir os grupos: 1- Trabalhadores Não Qualificados: com nível de ensino básico; 2- Trabalhadores Intermediários: referente ao ensino médio; 3- Trabalhadores Qualificados: indivíduos com nível de ensino superior.

Além desses três grupos de qualificação, também consideramos seis grupos de idade: Grupo 1: 26 a 30 anos; Grupo 2: 31 a 35 anos; Grupo 3: 36 a 40 anos; Grupo 4: 41 a 45 anos; Grupo 5: 46 a 50 anos; e Grupo 6: 51 a 55 anos. Qualquer indivíduo com idade não pertencente a qualquer um desses grupos não é considerado na nossa amostra para estimação. ${ }^{5} \mathrm{O}$ motivo para isso é que optamos por escolher os indivíduos a partir de uma idade em que provavelmente já tenham a sua escolaridade definida.

Construímos, portanto, o salário de um grupo de qualificação, ano a ano, como a média de salários de todos os indivíduos pertencentes ao grupo, sendo que cada salário é normalizado pelas horas semanais de trabalho. Para se construir um índice de salário referente a cada nível de ensino consideramos apenas os indivíduos com nível de ensino completo.

5 Todos os dados anuais foram obtidos a partir da Pesquisa Nacional por Amostra de Domicílio (PNAD). Ver capítulo III para mais detalhes. A amostra total de todos os indivíduos selecionados a partir dos dados anuais da PNAD é de 1.363.955. A participação dos grupos etários na amostra é a seguinte: Grupo 1: 20,45\%, Grupo 2: 20,22\%, Grupo 3: 19,36\%, Grupo 4: 17,06\%, Grupo 5: 13,32\% e Grupo 6: 9,58\%. 
Além disso, apenas consideramos os indivíduos com jornada de trabalho maior ou igual a 20 horas semanais. Todos os salários anuais são corrigidos também ano a ano pelo IPCA (Índice Nacional de Preços ao Consumidor Amplo).

Quanto à oferta de trabalho, esta corresponde às horas semanais de trabalho ${ }^{6}$ de todos os indivíduos pertencentes a um dos três níveis de ensino de referência. Para aqueles indivíduos que possuem algum grau de instrução incompleto é feita uma divisão na contabilização de sua oferta. As horas de oferta desse indivíduo são ponderadas pela distância entre o seu salário e os salários médios dos níveis de ensino de referência.

Tendo construído as medidas de salários e oferta, podemos analisar os resultados das estimativas das três etapas da metodologia descrita. Apresentamos as estimativas das Equações (7), (8) e (12), ${ }^{7}$ referentes às três etapas de estimação, sendo que em cada etapa temos estimativas de elasticidades de substituição entre tipos diferentes de trabalho. Na etapa final (12), quando já construímos as medidas de oferta agregada de trabalho, estão expostos os resultados de interesse. São eles: a estimativa da demanda relativa por trabalho qualificado e a elasticidade de substituição entre trabalho qualificado e não qualificado.

As Tabelas 2, 3 e 4 apresentam as três estimações referentes a cada etapa. Elas mostram as estimativas das regressões em mínimos quadrados ordinários, controladas pela heterocedasticidade, para as Equações (7), (8) e (12). Os coeficientes representam o negativo do inverso da elasticidade de substituição entre trabalhadores intermediários e não qualificados.

O resultado da primeira etapa ${ }^{8}$ apresentou um coeficiente para a medida de oferta relativa de trabalhadores não qualificados em relação aos intermediários significativos, com o valor de -0,107. A elasticidade de substituição $\sigma_{U}$ entre esses dois tipos de trabalhadores, portan-

${ }^{6}$ No apêndice B, também expomos os resultados das estimações considerando outras três medidas de oferta, além das horas semanais de trabalho; são elas: trabalhadores, população economicamente ativa (PEA) e população total. Os resultados mostraram-se semelhantes considerando essas diferentes medidas.

7 As estimativas das Equações (9), (10) e (11) estão na Tabela A3, no apêndice deste trabalho.

8 Nas Tabelas 2, 3 e 4 apresentamos apenas os principais coeficientes de interesse. Todos os coeficientes calculados para a primeira etapa, além dos coeficientes de interesse expostos aqui, estão apresentados na Tabela Al, no apêndice deste trabalho. 
to, será de 9,35. Isso significa que os trabalhadores não qualificados e intermediários (referentes ao nível de ensino básico completo e nível de ensino médio completo) não podem ser considerados substitutos perfeitos no mercado de trabalho brasileiro. Entretanto, a elasticidade calculada é bastante elevada, o que indica um alto nível de substituição entre esses dois tipos de trabalho (lembramos que quanto maior a elasticidade de substituição entre os trabalhadores, menos sensível é o diferencial de salários entre eles em relação a diferenças na oferta deles).

De acordo com o coeficiente calculado, identificamos que de fato é pequena a sensibilidade dos salários entre esses dois tipos de trabalho em relação à oferta. Quando a razão de oferta entre o trabalho intermediário e não qualificado aumenta em $1 \%$, o diferencial de salários entre esses dois tipos de trabalhadores diminui em aproximadamente $0,1 \%$. Portanto, concluímos nessa etapa que o salário relativo entre esses trabalhadores possui uma sensibilidade às mudanças na oferta relativa entre eles, embora essa seja uma pequena sensibilidade.

Tendo calculado $\sigma_{U}$, podemos construir uma medida da oferta anual agregada de trabalho de baixa qualificação $\left(N_{U \alpha t}\right)$. Ou seja, os trabalhadores intermediários e não qualificados são agregados de acordo com a elasticidade de substituição estimada em apenas um tipo de trabalho, que identificamos como de baixa qualificação (U). Calculada essa medida de oferta prosseguimos com a estimação da segunda etapa. A Tabela 4 expõe o resultado para a segunda etapa de estimação:Os resultados mostram que o coeficiente estimado para a oferta relativa dos grupos etários é de $-0,099$, o que significa que a elasticidade de substituição entre os grupos etários $\left(\sigma_{A}\right)$ é igual a 10,07 . Essa elasticidade é elevada, o que sugere um alto grau de substituição entre os grupos de idade no mercado de trabalho brasileiro. Para checar a consistência do modelo, nessa etapa o coeficiente $-1 / \sigma_{U}$ também foi calculado novamente, e apresentou um valor significativo e praticamente igual ao estimado na primeira etapa.

Com o conhecimento de $\sigma_{A}$ e $\sigma_{U}$, e também dos coeficientes das dummies referentes à produtividade dos grupos etários estimados nas Equações (9), (10) e (11), ${ }^{9}$ construímos uma medida da oferta anual agregada por idade, tanto para o trabalho de elevada qualificação

9 Ver Tabela A3 do apêndice. 
$\left(N_{3 t}\right)$ quanto para o de baixa qualificação $\left(N_{U t}\right)$. Calculadas essas medidas agregadas de oferta, podemos prosseguir com a estimação da terceira etapa. Na Tabela 5 mostramos os resultados para a terceira e última etapa de estimação, que é a de nosso interesse.

Os resultados da terceira etapa mostram que o coeficiente para a oferta relativa de trabalho de qualidade alta (nível de ensino superior) em relação ao de qualidade baixa (níveis de ensino médio ou básico) foi de -0.294 , a elasticidade de substituição $\sigma_{E}$ entre esses dois tipos de trabalho é de 3,39. A tendência de demanda relativa direcionada ao trabalho qualificado também foi significativa, apresentando um coeficiente de 0,012 , isto é, estimamos que o prêmio por qualificação cresça aproximadamente a uma taxa de $1,2 \%$ ao ano no período de 1992 a 2009.

Por fim, como um teste de consistência do modelo, esta etapa calcula novas estimativas para o coeficiente de oferta de cada grupo de idade $\left(-\frac{1}{\sigma_{A}}\right)$ e para o coeficiente da oferta relativa de trabalhadores não qualificados em relação aos intermediários $\left(-\frac{1}{\sigma_{U}}\right)$. As novas estimativas encontradas foram respectivamente de -0,097 e -0,107, o que denota uma elasticidade de substituição entre os grupos etários da ordem de 10,30 e elasticidade de substituição entre trabalhadores não qualificados em relação aos intermediários da ordem de $9,35 .{ }^{10}$ Novamente esses valores foram muito semelhantes aos resultados anteriores, o que comprova a consistência do modelo.

O valor calculado para $\sigma_{E}$ expressa que o trabalho de qualidade alta e o trabalho de qualidade baixa (este último engloba tanto os trabalhadores intermediários quanto os não qualificados) não podem ser considerados substitutos perfeitos no mercado de trabalho brasileiro. Esta foi a mesma conclusão que fizemos na etapa 1 referente aos trabalhadores intermediários e não qualificados $\left(\sigma_{U}\right)$. Entretanto, a elasticidade de substituição $\sigma_{E}$ calculada na etapa final foi menor do que calculado anteriormente, o que indica um grau de substituição menor entre o trabalho de qualificação alta e baixa. A elasticidade de substituição $\sigma_{E}$ calculada nessa etapa final foi de 3,39 . Isso significa que o aumento de uma unidade logarítmica na oferta diminui em

\footnotetext{
${ }^{10}$ Em seu estudo para a América Latina, Manacorda, Sanchez-Panamo e Schady (2010) encontram os seguintes coeficientes para as elasticidades de substituição: $\sigma_{U}=3,08, \sigma_{A}=13,70$ (não significativo), $\sigma_{E}=2,56$ e a tendência de demanda linear por trabalho qualificado de 0,004 (o que corresponde a um crescimento anual de $0,4 \%$ para o prêmio por qualificação).
} 
0,29 o logaritmo do prêmio por qualificação, ou seja, um aumento de $1 \%$ na oferta relativa de trabalho qualificado reduz em aproximadamente $0,3 \%$ o salário desse tipo de trabalho em relação ao trabalho de baixa qualificação.

O Gráfico 2 mostra como o modelo se ajusta aos dados observados, para cada grupo etário. ${ }^{11}$ Analisando os diferencias de salários entre indivíduos de qualificação alta e baixa por grupo de idade, verificamos uma tendência de crescimento do diferencial durante a década de 1990 para todos os grupos. A partir da virada do século o crescimento do prêmio passa a ser menor e eventualmente o prêmio começa a decrescer para a maioria dos grupos. Entretanto, para os maiores grupos etários (5 e 6, representando os trabalhadores de 46 a 55 anos) estimamos que o padrão de crescimento do prêmio da década de 1990, grosso modo, se mantém durante a década de 2000. Apesar de que para esses grupos o diferencial de salários observado é mais oscilante. Essa análise complementa o que verificamos no Gráfico 9, os trabalhadores com maior idade (46 a 55 anos) passaram a ser mais valorizados no mercado de trabalho brasileiro, sendo que essa valorização foi mais acentuada nos trabalhadores qualificados (com ensino superior).

Vale lembrar que o modelo final considera conjuntamente o efeito do diferencial de oferta entre trabalhadores de elevada e baixa qualificação e da demanda por qualificação representada pelo crescimento linear do prêmio. O Gráfico 3 faz uma simulação de como seriam os valores estimados para o prêmio, agregado para todos os grupos de idade, caso eliminássemos o efeito da oferta ou da demanda.

De acordo a relação estimada pelo modelo final, podemos encontrar o impacto da variação da oferta sobre o prêmio por qualificação. Considerando a década de 90 , temos que a razão entre oferta de alta qualificação (com ensino superior completo) e baixa qualificação (com ensino médio ou ensino básico completo, já agregados pelos coeficientes estimados nas etapas 1 e 2) aumentou cerca de $6 \%$ entre 1992 e 1999. Combinando esse aumento de 6\% do diferencial de oferta com o coeficiente calculado para ela $(-0,294)$, teremos que o prêmio por qualificação se reduz em $1,8 \%$, caso não haja alteração nas demais variáveis do modelo. Realizando esse mes-

${ }^{11} \mathrm{O}$ Gráfico $\mathrm{Cl}$, no apêndice, ilustra como os salários se diferenciam de acordo com o grupo etário em questão. 
mo exercício para o novo milênio, temos que a razão entre oferta de trabalho de qualidade alta e baixa aumentou 37,2\% entre 2002 e 2009. Considerando o coeficiente estimado para o diferencial de oferta $(-0,294)$, esse aumento impulsiona uma redução de aproximadamente $11 \%$ no prêmio por qualificação.

Combinando esses impactos calculados para a oferta com a tendência linear de crescimento do prêmio por qualificação ${ }^{12}$ (cerca de $1,2 \%$ por ano), temos que na década de 90 a tendência de aumento do prêmio foi mais forte do que os efeitos negativos, oferta relativa verificada nessa década. Pelo efeito da demanda (representada pela tendência linear de crescimento), o diferencial de salários se eleva em 9,6\%; pelo efeito da oferta, reduz-se em 1,8\%. O resultado disso é que estimamos que o prêmio por qualificação se elevou em $7,8 \%$ de 1992 a 1999. Alternativamente, para o período de 2001 a 2009, vimos que o crescimento da oferta relativa de trabalho qualificado foi marcante. Mesmo considerando para esse período a tendência de crescimento linear do prêmio, os efeitos negativos da grande elevação da oferta determinaram uma redução do prêmio por qualificação em cerca de $0,2 \%$.

Concluímos, portanto, que para o período considerado de 1992 a 2009 no mercado de trabalho brasileiro, verificamos dois resultados distintos. Inicialmente, para o período de 1992 a 1999, e considerando conjuntamente trabalhadores de todas as idades, os efeitos da oferta sobre o prêmio por qualificação não foram grandes o suficiente para compensar os efeitos de demanda. O resultado disso é que o prêmio por qualificação aumentou nesse período em 7,8 pontos percentuais. Já para o período de 2001 a 2009, o grande aumento da oferta relativa do trabalho de maior qualificação impulsionou uma pequena queda de 0,2 pontos percentuais no prêmio por qualificação. Quando analisamos a evolução do prêmio especificamente para cada grupo de idade, vemos que esse padrão de elevação do prêmio seguido de queda persiste para a maioria dos grupos. Entretanto, para os grupos de idade mais velhos (46 a 55 anos) observamos que, grosso modo, o prêmio para o período de 2002 a 2009 mantém a tendência de crescimento ao longo de todo o período considerado.

12 Lembramos que a tendência linear de crescimento do prêmio representa todos os efeitos de demanda por trabalho qualificado. 
Esse último fato indica que trabalhadores qualificados e de maior idade tiveram uma valorização no mercado de trabalho brasileiro no período de 1992 a 2009.

\subsection{Resultados - Tendência Quadrática}

Nesta seção nos re-estimamos a equação final do modelo, porém considerando um crescimento quadrático para a demanda por trabalho qualificado. A nova equação a ser estimada é:

$$
\begin{gathered}
w_{3 a t}-w_{e a t}=f_{0}^{\prime}-f_{1} t+f_{2} t^{2}+d_{e a} \\
-1 / \sigma_{E}\left(n_{3 t}-n_{U t}\right)-1 / \sigma_{A}\left[\left(n_{U t}-n_{U a t}\right)-\left(n_{3 t}-n_{3 a t}\right)\right]-1 / \sigma_{u}\left(n_{\text {Uat }}-n_{\text {eat }}\right) \\
\mathrm{e}=1,2
\end{gathered}
$$

A Tabela 5 expõe as novas estimativas encontradas. A primeira grande novidade é que o coeficiente quadrático estimado para a demanda é altamente significativo e com sinal negativo. O coeficiente linear continuou positivo e significativo, com uma magnitude maior (0.34). Quanto aos coeficientes da oferta, pode-se verificar que o da oferta relativa de trabalhadores não qualificados em relação aos intermediários $\left(-1 / \sigma_{u}\right)$ e o da oferta relativa dos grupos etários $\left(-1 / \sigma_{A}\right)$ apresentaram valores praticamente iguais aos estimados anteriormente. Por sua vez, e mais importante, o coeficiente da oferta relativa de trabalho qualificado em relação ao de baixa qualificação $\left(-1 / \sigma_{E}\right)$ apresentou uma menor significância e uma menor magnitude $(-0,106)$.

A análise gráfica dessa nova especificação (Gráfico 4) mostra um ajuste melhor dos valores estimados aos dados reais. Ao analisar o efeito separado da oferta e da demanda (Gráfico 5), é possível perceber que o efeito da demanda quadrática agora é mais relevante para explicar a evolução do prêmio por qualificação do que a oferta relativa de trabalho qualificado.

Os resultados mostram que podem existir outros fatores, além da oferta, que impulsionaram a redução do prêmio por qualificação verificada durante a última década. O coeficiente negativo estimado 
para o termo quadrático da demanda corrobora isso. Ele indica que, à medida que passa o tempo, a tendência de redução do prêmio por qualificação é intensificada (já controlando pela maior oferta relativa de trabalho qualificado). Neste trabalho não investigamos quais são esses motivos e os seus reais impactos, mas é bem provável que o aumento do salário mínimo e maior demanda por trabalhos que não exigem elevada qualificação sejam causas importantes dessa redução recente do prêmio por qualificação. Um complemento natural a este estudo seria uma investigação da relação entre esses fatores e o prêmio por qualificação.

\section{Conclusões}

O objetivo deste trabalho foi entender o impacto da evolução da oferta e da demanda por trabalho qualificado sobre os diferenciais de salários dos trabalhadores no Brasil. Para isso, utilizamos dados das PNADs para os anos de 1992 a 2009 e trabalhamos com salários e oferta de trabalho referentes a três grupos de qualificação: ensino básico completo (não qualificados), ensino médio completo (intermediários), e ensino superior completo (qualificados).

Através do uso de um modelo de oferta e demanda por trabalho qualificado, encontramos estimativas significativas que indicaram a existência de uma elasticidade de substituição entre trabalho de qualidade alta e baixa (este último tipo de trabalho agrega tanto os intermediários quanto os não qualificados) da ordem de 3,39. Isso significa que o diferencial de salários entre esses dois tipos de trabalho é sensível a diferenças na oferta deles, tendo em vista que para a produção da economia eles não são perfeitamente substituíveis. De acordo com essa elasticidade, um aumento de $1 \%$ na oferta relativa de trabalho qualificado reduz em aproximadamente $0,3 \%$ o diferencial entre trabalho de elevada e baixa qualificação. Também encontramos estimativas significativas para o efeito linear da demanda por trabalho qualificado da ordem de 0,012 , ou seja, estimamos que o prêmio por qualificação (diferencial de salários entre trabalhadores de qualidade elevada e baixa) cresce à taxa de 1,2 pontos percentuais ao ano devido a esse aumento da demanda. 
Analisando os movimentos de oferta acontecidos durante o período de 1992 a 2009, e combinando-os com os efeitos da demanda estimados, verificamos dois movimentos distintos para o prêmio por qualificação. Inicialmente, entre 1992 e 1999, estimamos uma elevação do prêmio por qualificação na ordem de 7,8 pontos percentuais, causado principalmente pelo efeito da demanda relativa por trabalho qualificado. No período de 2001 a 2009, o efeito do diferencial de oferta foi marcante. Verificamos para esse período um grande aumento da oferta de trabalho qualificado que determinou a redução de 0,2 pontos percentuais no prêmio por qualificação, mesmo considerando os efeitos da demanda existentes nesse período. Ao permitirmos uma tendência de crescimento não linear da demanda, os resultados sugerem que outros fatores, além da oferta, impulsionaram a redução do prêmio por qualificação verificada durante a última década. Prováveis candidatos para esse último efeito encontrado são o aumento real do salário mínimo (ver Firpo e Reis, 2007) e a maior demanda por empregos que não exigem elevado nível de educação (ver Firpo, Fortin e Lemieux, 2011).

Quando detalhamos essa análise para seis grupos de idade (25 a 30 anos, 31 a 35 anos, 36 a 40 anos, 41 a 45 anos, 46 a 50 anos e 51 a 55 anos), notamos esse mesmo padrão de elevação do prêmio seguida de queda com exceção dos dois maiores grupos de idade. Nestes grupos, o prêmio por qualificação, apesar de apresentar um padrão mais oscilante, elevou-se durante todo o período considerado. Esse fato indica que trabalhadores qualificados e de mais idade foram mais valorizados no mercado de trabalho brasileiro.

Ressaltamos que todos os trabalhos citados aqui que analisam o prêmio por qualificação no Brasil apontam para o crescimento do prêmio, por diversos motivos. Entretanto, esses estudos se estendem no máximo até o ano de 2002. Os resultados encontrados aqui são relevantes, pois complementam trabalhos anteriores da literatura, ${ }^{13}$ uma vez que se evidencia um cenário mais recente de queda para o prêmio. Portanto, partindo dos resultados e limitações do nosso estudo, uma questão importante que requer maior atenção estaria em nova investigação acerca dos determinantes da demanda relativa por trabalho qualificado, simplificados neste trabalho pelas tendências linear e quadrática.

${ }^{13}$ Ver Manacorda, Sanchez-Panamo e Schady (2010), Menezes-Filho e Rodrigues Jr. (2003), Giovannetti e Menezes-Filho (2007) e Bressan e Hermeto (2008). 
Sugerimos, portanto, uma extensão dos estudos acerca dos determinantes que atuam na oferta e na demanda por qualificação para um período mais recente.

Outra análise que seria pertinente, partindo da metodologia aqui abordada, seria a de considerar mais um grupo de qualificação: o de pós-graduação. Neste trabalho, avaliamos os indivíduos pós-graduados como qualificados, ou seja, eles estão no mesmo grupo de qualificação que os indivíduos com ensino superior. Lindley e Machin (2011) analisam para os Estados Unidos, utilizando uma metodologia muito semelhante à que seguimos aqui, a oferta e a demanda por qualificação focando nos trabalhadores com pós-graduação. $\mathrm{O}$ estudo desses autores poderia ser aplicado ao caso brasileiro recente.

\section{Referências}

ACEMOGLU, D. e AUTOR, D. (2011), "Skills, Tasks, and Technologies: Implications for Employment and Earnings" in O. Ashenfelter and D. Card, eds., Handbook of Economics, Amsterdam: North-Holland, Vol. IV.B: 1043-1172.

ATKINSON, A.; PIKETTY T.; SAEZ E. (2011). “Top Incomes in the Long Run of History,” Journal of Economic Literature, American Economic Association, vol. 49(1), pages 3-71, March.

AUTOR, D.; LAWRENCE F.; KRUEGER, A. (1998). "Computing Inequality: Have Computers Changed The Labor Market?," The Quarterly Journal of Economics, MIT Press, vol. 113(4), pages 1169-1213.

AUTOR, D.; KATZ, L.; KEARNEY, M. (2006). “The Polarization of the U.S. Labor Market,” NBER Working Papers 11986, National Bureau of Economic Research, Inc.

BARROS, R. P.; FOGUEL, M.; ULYSSEA, G. (2006), "Sobre a Recente Queda da Desigualdade de Renda no Brasil”. In: BARROS, R. P.; FOGUEL, M.; ULYSSEA, G. (org) Desigualdade de renda no Brasil: uma análise da queda recente. - Brasília: IPEA, Nota técnica. v.1.

BONELLI, R. e RAMOS, L. (1995) "Distribuição de Renda no Brasil: Avaliação das Tendências de Longo Prazo e Mudanças na Desigualdade desde Meados dos Anos 70”, Revista Brasileira de Economia, vol. 49, pp. 353-73.

BRESSAN, G. S.; HERMETO. "Polarização do mercado de trabalho sob viés tecnológico e impactos sobre diferenciais salariais por gênero". In: XXXVII Encontro Nacional de Economia, 2009, Foz do Iguaçu. TRABALHOS APROVADOS, 2009.

CACCIAMALI, M. (1991) “As Economias Informal e Submersa: Conceitos e Distribuição de renda”, in Camargo e Giambiagi (eds) Distribuição de Renda no Brasil. Paz e Terra.

CAMARGO, J. e NÉRI, M. (1999) "Distributive Effects of the Brazilian Structural Reforms", Anais do XXVII Encontro Nacional de Economia, pp. 1845-1868.

CARD, D. e LEMIEUX, T. (2001). "Can Falling Supply Explain the Rising Return to College for Younger Men?" Quarterly Journal of Economics 116, 705-746. 
CARNEIRO, P. e LEE, S. (2009). "Estimating distributions of potential outcomes using instrumental variables with an application to changes in college enrolment and wage inequality", Abril 2009, Journal of Econometrics, Vol. 149, No. 2, pp. 191-208, Elsevier, Journal Articles.

FIRPO, S., FORTIN N., e LEMIEUX T. (2011). “Occupational Tasks and Changes in the Wage Structure." Working paper,

FIRPO, S. \& REIS, M. C. (2007), O salário mínimo e a queda recente da desigualdade no Brasil, in 'Desigualdade de renda no Brasil: uma análise da queda recente. Vol. 2. Brasília', IPEA.

FERNANDES, R; MENEZES-FILHO, N. (2012) "Educação, Salários e a Alocação de Trabalhadores entre Tarefas: Teoria e evidências para o Brasil”. Pesquisa e Planejamento Econômico, 42, n.3, 239-56.

GIOVANETTI, B.; MENEZES-FILHO, N. (2006). Trade Liberalization and Demand for Skill in Brazil Economía (LACEA): 7, no.1, 1-28.

GONZAGA, G.; MENEZES-FILHO, N. A.; TERRA, C. (2005) "Trade liberalization and earnings differentials in Brazil”. Journal of International Economics, v. 68, n. 2, p. 345-367.

HENRIQUES, R., (2001). Desigualdade Racial no Brasil: Evolução das Condições de Vida na Década de 90. Texto para Discussão 807. Rio de Janeiro: Instituto de Pesquisa Econômica Aplicada.

HOFFMANN, R. (1995) “A Desigualdade e Pobreza no Brasil no Período 1979-90”, Revista Brasileira de Economia, vol.49, pp.277-94.

KATZ, L.; MURPHY, K. (1992). Changes in relative wages: supply and demand factors. Quarterly Journal of Economics, v. 107, p. 35-78

LAM, D. e SCHOENI, R. (1973) "Effects of Family Background on Earning and Returns to Schooling: Evidence from Brasil”, Journal of Political Economy, vol. 101, pp.711-738.

LINDLEY, J. e MACHIN, S. (2011). "Rising Wage Inequality and Postgraduate Education”, DP1075, Centre for Economic Performance, London School of Economics.

MANACORDA, SÁNCHEZ-PÁRAMO e SCHADY, (2010). “Changes in Returns to Education in Latin America: The Role of Demand and Supply of Skills," Industrial and Labor Relations Review, ILR Review, ILR School, Cornell University, vol. 63, No. 2 (jan.), pp. 307-326.

MENEZES-FILHO, N. e RODRIGUES, M. (2003). “Tecnologia e Demanda por Qualificação na Indústria Brasileira". Revista Brasileira de Economia, Vol. 57, No 3.

MENEZES-FILHO, N. e TAVARES, P. (2011). "Human Capital and the Recent Fall of Earnings Inequality in Brasil”. Universidade de São Paulo, mimeo. 


\section{GRÁFICOS E TABELAS}

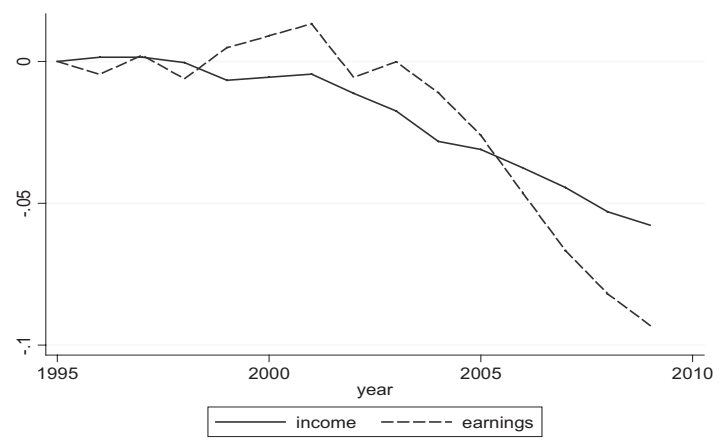

\section{Gráfico 1 - Variação, a partir do nível inicial em 1995, dos coeficientes de Gini} para a renda per capita e para os salários. 1995 - 2010

Fonte: Menezes Filho e Tavares (2011)

Nota: Dados das PNADs de 1995 a 2009 e IPEADATA.

income (linha cheia) $=$ desigualdade de renda. earnings (linha tracejada) $=$ desigualdade salarial

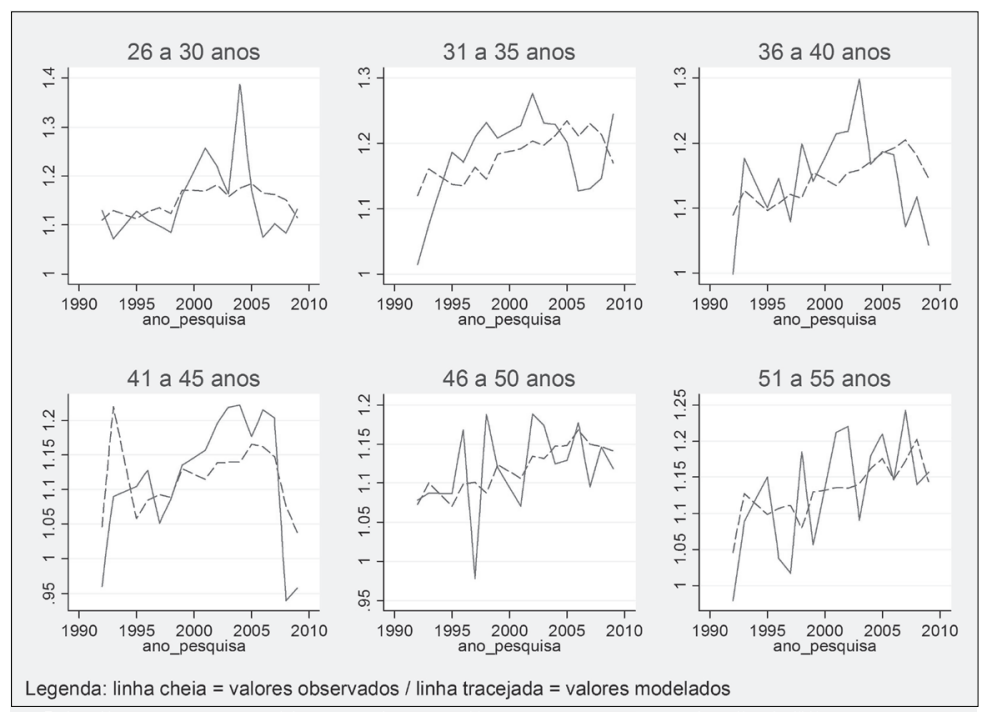

Gráfico 2 - Média anual estimada e observada, por grupo etário, dos diferenciais de salários entre trabalhadores de alta qualificação e baixa qualificação. 1992 - 2009

Fonte: Cálculos próprios a partir dos resultados obtidos na Tabela 3.

As linhas cheias expõem a média anual do diferencial de salários observados entre o trabalho de alta qualidade e baixa qualidade $\left(w_{3 a t}-w_{\text {eat }}\right.$, onde $\left.e=1,2\right)$. As linhas tracejadas expõem a média anual dos valores estimados pelo modelo (equação 12) para o diferencial de salários. 


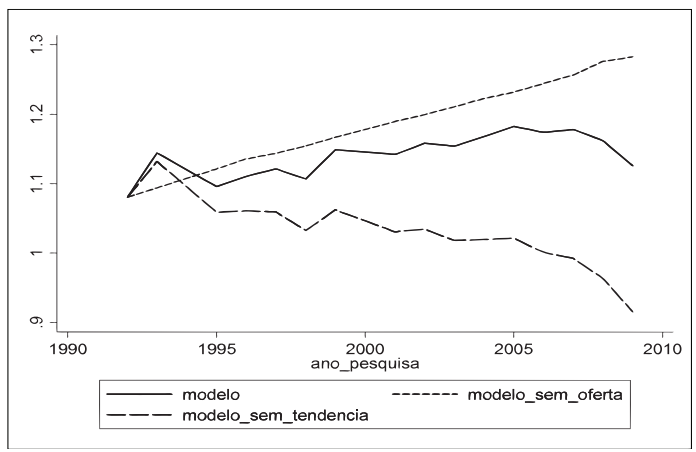

\section{Gráfico 3 - Efeitos da oferta relativa de trabalho qualificados e da demanda linear por trabalho qualificado}

Fonte: Cálculos próprios a partir dos resultados obtidos na Tabela 3.

As séries foram obtidas eliminando o efeito das variáveis de oferta e de demanda. A linha com traços curtos mostra o efeito apenas da demanda linear por trabalho qualificado. Para obter essa série calculamos os valores estimados pelo modelo fixando o diferencial de oferta para o seu valor inicial observado em 1992. A linha com traços longos mostra o efeito apenas do diferencial de oferta entre trabalhadores de elevada e baixa qualificação. Essa série foi obtida calculando os valores estimados para o prêmio por qualificação quando a variável linear de tendência de crescimento do prêmio foi zerada. Para critério de comparação, expomos novamente o modelo final (linha cheia) que considera conjuntamente os efeitos de oferta e demanda.

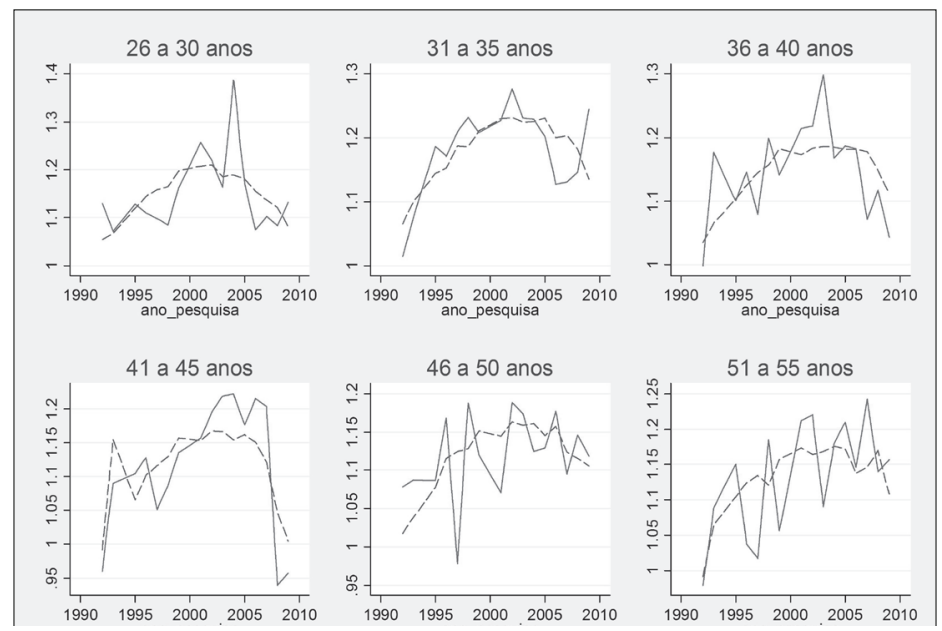

Gráfico 4 - Média anual estimada (com crescimento quadrático da demanda) e observada, por grupo etário, dos diferenciais de salários entre trabalhadores de alta qualificação e baixa qualificação. 1992 - 2009

Fonte: Cálculos próprios a partir dos resultados obtidos na Tabela 5.

As linhas cheias expõem a média anual do diferencial de salários observados entre o trabalho de alta qualidade e baixa qualidade $\left(w_{3 a t}-w_{\text {eat }}\right.$, onde $\left.e=1,2\right)$. As linhas tracejadas expõem a média anual dos valores estimados pelo modelo (equação 13) para o diferencial de salários. 


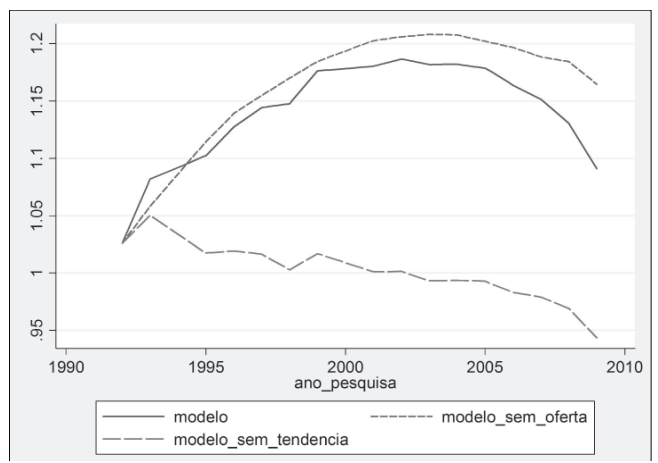

\section{Gráfico 5 - Efeitos da oferta relativa de trabalho qualificados e da demanda quadrática por trabalho qualificado}

Fonte: Cálculos próprios a partir dos resultados obtidos na Tabela 5.

As séries foram obtidas eliminando o efeito das variáveis de oferta e de demanda. A linha com traços curtos mostra o efeito apenas da demanda quadrática por trabalho qualificado. Para obter essa série calculamos os valores estimados pelo modelo fixando o diferencial de oferta para o seu valor inicial observado em 1992. A linha com traços longos mostra o efeito apenas do diferencial de oferta entre trabalhadores de elevada e baixa qualificação. Essa série foi obtida calculando os valores estimados para o prêmio por qualificação quando as variáveis de tendência temporal foram zeradas. Para critério de comparação, expomos novamente o modelo final (linha cheia) que considera conjuntamente os efeitos de oferta e demanda.

Tabela 1 - Retornos para a educação e diferentes medidas de oferta por nível de educação - 1992-2009

\begin{tabular}{|c|c|c|c|c|}
\hline & & 1992 & 2001 & 2009 \\
\hline \multirow{2}{*}{ RETORNOS PARA A EDUCAÇÃO } & Qualificados/Intermediários & 1,367 & 1,560 & 1,334 \\
\hline & Intermediários/Não qualificados & 0,696 & 0,726 & 0,509 \\
\hline \multirow{3}{*}{ POPULAÇÃO } & \% Não qualificados & 56,0 & 42,1 & 25,3 \\
\hline & $\%$ Intermediários & 33,0 & 45,7 & 59,0 \\
\hline & $\%$ Qualificados & 11,0 & 12,2 & 15,7 \\
\hline \multirow{3}{*}{ PEA } & $\%$ Não qualificados & 53,1 & 39,8 & 23,1 \\
\hline & $\%$ Intermediários & 34,4 & 46,7 & 59,8 \\
\hline & $\%$ Qualificados & 12,5 & 13,5 & 17,1 \\
\hline \multirow{3}{*}{ EMPREGADOS } & $\%$ Não qualificados & 51,1 & 37,3 & 22,0 \\
\hline & $\%$ Intermediários & 35,5 & 48,4 & 60,2 \\
\hline & $\%$ Qualificados & 13,5 & 14,3 & 17,8 \\
\hline \multirow{3}{*}{ HORAS } & $\%$ Não qualificados & 53,8 & 39,0 & 22,3 \\
\hline & $\%$ Intermediários & 34,1 & 47,9 & 61,2 \\
\hline & $\%$ Qualificados & 12,1 & 13,1 & 16,5 \\
\hline
\end{tabular}

Fonte: MANACORDA, SANCHEZ-PANAMO e SCHADY (2010).

Nota: Coeficientes para as duas dummies de educação estão expostas nas primeiras duas linhas da tabela. As demais linhas mostram as médias anuais da distribuição da população, da PEA, dos empregados e das horas trabalhadas, entre os três grupos de qualificação. 
Tabela 2 - Primeira etapa: estimação dos diferenciais de salários por grupo de idade e ano entre trabalhadores intermediários e não qualificados

\begin{tabular}{cc}
\hline$-1 / \sigma_{U}$ & $-0,107^{\star \star \star}$ \\
Número de observações & $(0.030)$ \\
$\mathrm{R}^{2}$ & 96 \\
\hline
\end{tabular}

${ }^{*}$ Estatisticamente significativo a $10 \%$ de confiança; ${ }^{* *}$ a $5 \%$ de confiança, ${ }^{* * *}$ a $1 \%$ de confiança (testes bicaudais). Desvios padrão em parênteses.

Nota: Expomos apenas os coeficientes do termo de oferta da Equação (11) Nessa etapa $\sigma_{u}$ é identificado.

Tabela 3 - Segunda etapa: estimação dos diferenciais de salários por grupo de idade e ano entre trabalhadores qualificados e trabalhadores de baixa qualificação

\begin{tabular}{|c|c|}
\hline$-1 / \sigma_{A}$ & $\begin{array}{c}-0,099^{\star *} \\
(0.044)\end{array}$ \\
\hline$-1 / \sigma_{U}$ & $\begin{array}{c}-0,107^{\star \star *} \\
(0.028)\end{array}$ \\
\hline Número de observações & 192 \\
\hline $\mathrm{R}^{2}$ & 0,99 \\
\hline
\end{tabular}

* Estatisticamente significativo a $10 \%$ de confiança; ${ }^{* *}$ a $5 \%$ de confiança, ${ }^{* * *}$ a $1 \%$ de confiança (testes bicaudais). Desvios padrão em parênteses.

Nota: Expomos apenas os coeficientes do termo de oferta da Equação (12) Nessa etapa $\sigma_{A}$ é identificado e temos uma nova estimativa para $\sigma_{u}$.

Tabela 4 - Terceira etapa: estimação dos diferenciais de salários por grupo de idade e ano entre trabalhadores qualificados e trabalhadores de baixa qualificação

\begin{tabular}{|c|c|}
\hline Tendência de demanda por trabalho qualificado & $\begin{array}{c}0,012^{\star \star \star} \\
(0.002)\end{array}$ \\
\hline$-1 / \sigma_{E}$ & $\begin{array}{c}-0,294^{\star \star \star} \\
(0.082)\end{array}$ \\
\hline$-1 / \sigma_{A}$ & $\begin{array}{l}-0,097^{\star} \\
(0.051)\end{array}$ \\
\hline$-1 / \sigma_{U}$ & $\begin{array}{c}-0,107^{\star \star \star} \\
(0.031)\end{array}$ \\
\hline Número de observações & 192 \\
\hline $\mathrm{R}^{2}$ & 0,96 \\
\hline
\end{tabular}

* Estatisticamente significativo a $10 \%$ de confiança; ${ }^{* *}$ a $5 \%$ de confiança, ${ }^{* * *}$ a $1 \%$ de confiança (testes bicaudais). Desvios padrão em parênteses.

Nota: Expomos apenas os coeficientes da demanda e dos termos de oferta da Equação (16).

Nessa etapa a tendência de demanda e $\sigma_{E}$ são identificados, e temos novas estimativas para $\sigma_{A}$ e $\sigma_{u}$ 
Tabela 5 - Terceira etapa: estimação dos diferenciais de salários por grupo de idade e ano entre trabalhadores qualificados e trabalhadores de baixa qualificação, com tendência quadrática

\begin{tabular}{|c|c|}
\hline $\mathrm{T}$ & $\begin{array}{c}0,034^{\star \star \star} \\
(0.003)\end{array}$ \\
\hline$[T]^{2}$ & $\begin{array}{c}-0,011^{\star \star \star} \\
(0.001)\end{array}$ \\
\hline$-1 / \sigma_{E}$ & $\begin{array}{l}-0,138^{\star} \\
(0.084)\end{array}$ \\
\hline$-1 / \sigma_{A}$ & $\begin{array}{c}-0,094^{* *} \\
(0.042)\end{array}$ \\
\hline$-1 / \sigma_{U}$ & $\begin{array}{c}-0,106^{\star \star \star} \\
(0.026)\end{array}$ \\
\hline Número de observações & 192 \\
\hline $\mathrm{R}^{2}$ & 0,97 \\
\hline
\end{tabular}

*Estatisticamente significativo a $10 \%$ de confiança; ${ }^{* *}$ a $5 \%$ de confiança, ${ }^{* * *}$ a $1 \%$ de confiança (testes bicaudais). Desvios padrão em parênteses.

Nota: Expomos apenas os coeficientes da demanda e dos termos de oferta da Equação (16). Nessa etapa a tendência de demanda e $\sigma_{E}$ são identificados, e temos novas estimativas para $\sigma_{A}$ e $\sigma_{u}$.

\section{Apêndice A - Resultados Completos}

Tabela A.1 - Primeira etapa: todos os coeficientes da estimação dos diferenciais de salários por grupo de idade e ano entre trabalhadores intermediários e trabalhadores não qualificados (Equação 11)

Diferencial entre intermediários e não qualificados

\begin{tabular}{|c|c|c|}
\hline 20 a 25 anos & $0.764^{\star \star \star}$ & $(0.032)$ \\
\hline 31 a 35 anos & $0.780^{\star \star \star}$ & $(0.027)$ \\
\hline 36 a 40 anos & $0.785^{\star \star \star}$ & $(0.018)$ \\
\hline 41 a 45 anos & $0.751^{\star \star \star}$ & $(0.017)$ \\
\hline 46 a 50 anos & $0.716^{\star \star *}$ & $(0.028)$ \\
\hline 51 a 55 anos & $0.682^{\star \star \star *}$ & $(0.033)$ \\
\hline
\end{tabular}

Coeficiente do Diferencial de Oferta

Entre grupos de educação

(intermediários - não qualificados)

$-0.107$

0.030

Número de observações $\quad 96$

$\mathrm{R}^{2}$

0,98

*Estatisticamente significativo a $10 \%$ de confiança; **a $5 \%$ de confiança, ${ }^{* * *}$ a $1 \%$ de confiança (testes bicaudais). Desvios padrão em parênteses. 
Gráfico A.1 - Primeira etapa (Equação 11): média anual estimada e observada dos diferenciais de salários entre trabalhadores intermediários e não qualificados. 1992 - 2009

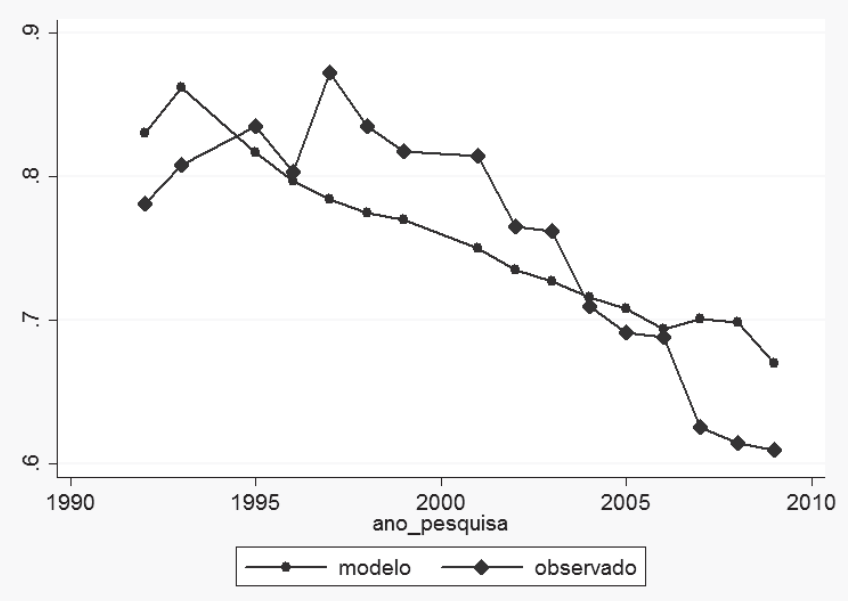


Tabela A.2 - Segunda etapa: todos os coeficientes da estimação dos diferenciais de salários por ano e grupo de idade entre trabalhadores qualificados e trabalhadores de baixa qualificação (Equação 12)

\begin{tabular}{|c|c|c|}
\hline \multicolumn{3}{|l|}{ Diferencial entre Qualificados e Não Qualificados } \\
\hline 1992 & $1.297^{\star \star \star}$ & $(0.118)$ \\
\hline 1993 & $1.351^{\star \star \star}$ & $(0.121)$ \\
\hline 1995 & $1.401^{\star \star \star}$ & $(0.118)$ \\
\hline 1996 & $1.400^{\star \star \star}$ & $(0.119)$ \\
\hline 1997 & $1.349^{\star * \star}$ & $(0.120)$ \\
\hline 1998 & $1.449^{\star \star *}$ & $(0.115)$ \\
\hline 1999 & $1.414^{\star \star \star}$ & $(0.120)$ \\
\hline 2001 & $1.478^{\star \star \star}$ & $(0.119)$ \\
\hline 2002 & $1.509^{\star * *}$ & $(0.117)$ \\
\hline 2003 & $1.491^{\star \star \star}$ & $(0.115)$ \\
\hline 2004 & $1.513^{\star \star \star}$ & $(0.119)$ \\
\hline 2005 & $1.476^{\star \star \star}$ & $(0.114)$ \\
\hline 2006 & $1.457^{\star \star \star}$ & $(0.114)$ \\
\hline 2007 & $1.447^{\star \star \star}$ & $(0.113)$ \\
\hline 2008 & $1.407^{\star \star \star}$ & $(0.111)$ \\
\hline 2009 & $1.440^{\star \star \star}$ & $(0.107)$ \\
\hline 20 a 25 anos (referência) & - & - \\
\hline 31 a 35 anos & 0.039 & $(0.039)$ \\
\hline 36 a 40 anos & 0.008 & $(0.043)$ \\
\hline 41 a 45 anos & -0.035 & $(0.047)$ \\
\hline 46 a 50 anos & -0.055 & $(0.044)$ \\
\hline 51 a 55 anos & 0.066 & $(0.047)$ \\
\hline Diferencial entre Qualificados e Intermediários & $-0.764^{\star \star \star}$ & $(0.036)$ \\
\hline 20 a 25 anos (referência) & - & - \\
\hline 31 a 35 anos & -0.016 & $(0.038)$ \\
\hline 36 a 40 anos & -0.020 & $(0.042)$ \\
\hline 41 a 45 anos & 0.013 & $(0.042)$ \\
\hline 46 a 50 anos & 0.048 & $(0.053)$ \\
\hline 51 a 55 anos & 0.082 & $(0.063)$ \\
\hline \multicolumn{3}{|l|}{ Coeficientes do Diferencial de Oferta } \\
\hline Entre grupos de idade & $-0.099^{\star \star}$ & $(0.044)$ \\
\hline $\begin{array}{l}\text { Entre grupos de educação } \\
\text { (intermediários - não qualificados) }\end{array}$ & $-0.107^{\star \star \star}$ & $(0.028)$ \\
\hline Número de observações & 192 & \\
\hline $\mathrm{R}^{2}$ & 0,96 & \\
\hline
\end{tabular}

${ }^{*}$ Estatisticamente significativo a $10 \%$ de confiança; ${ }^{* *}$ a $5 \%$ de confiança, ${ }^{* * *}$ a $1 \%$ de confiança (testes bicaudais). Desvios padrão em parênteses. 
Tabela A.3 - Segunda etapa: todos os coeficientes da estimação dos salários médios por ano e grupos de idade

\begin{tabular}{|c|c|c|c|c|c|c|}
\hline Ano & \multicolumn{2}{|c|}{$\begin{array}{l}\text { Equação (13) - Salário } \\
\text { Médio dos Qualificados }\end{array}$} & \multicolumn{2}{|c|}{$\begin{array}{l}\text { Equação (14) - Salário } \\
\text { Médio dos Intermediários }\end{array}$} & \multicolumn{2}{|c|}{$\begin{array}{l}\text { Equação (15) - Salário } \\
\text { Médio dos Não Qualificado }\end{array}$} \\
\hline 1992 & $8.553^{\star \star \star}$ & $(0.019)$ & $7.996^{\star \star \star}$ & $(0.011)$ & $8.045^{\star \star \star}$ & $(0.020)$ \\
\hline 1993 & $1.509^{\star \star \star}$ & $(0.029)$ & $0.895^{\star \star \star}$ & $(0.015)$ & $0.949^{\star \star \star}$ & $(0.023)$ \\
\hline 1995 & $9.535^{\star \star *}$ & $(0.019)$ & $8.908^{\star \star *}$ & $(0.018)$ & $8.889^{\star \star \star}$ & $(0.020)$ \\
\hline 1996 & $9.538^{\star \star \star}$ & $(0.026)$ & $8.906^{\star \star \star}$ & $(0.023)$ & $8.900^{\star \star \star}$ & $(0.018)$ \\
\hline 1997 & $9.462^{\star \star *}$ & $(0.041)$ & $8.922^{\star \star \star}$ & $(0.017)$ & $8.834^{\star \star \star}$ & $(0.015)$ \\
\hline 1998 & $9.500^{\star \star *}$ & $(0.020)$ & $8.845^{\star \star \star}$ & $(0.017)$ & $8.784^{\star \star \star}$ & $(0.019)$ \\
\hline 1999 & $9.380^{\star \star *}$ & $(0.026)$ & $8.754^{\star \star \star}$ & $(0.019)$ & $8.707^{\star \star \star}$ & $(0.016)$ \\
\hline 2001 & $9.374^{\star \star *}$ & $(0.033)$ & $8.692^{\star \star \star}$ & $(0.015)$ & $8.628^{\star \star *}$ & $(0.029)$ \\
\hline 2002 & $9.334^{\star \star *}$ & $(0.026)$ & $8.605^{\star \star \star}$ & $(0.017)$ & $8.575^{\star \star \star}$ & $(0.027)$ \\
\hline 2003 & $9.290^{\star \star \star}$ & $(0.040)$ & $8.580^{\star \star \star}$ & $(0.014)$ & $8.545^{\star \star \star}$ & $(0.025)$ \\
\hline 2004 & $9.300^{\star \star \star}$ & $(0.020)$ & $8.547^{\star \star \star}$ & $(0.013)$ & $8.554^{\star \star \star}$ & $(0.016)$ \\
\hline 2005 & $9.275^{\star \star \star}$ & $(0.022)$ & $8.555^{\star \star \star}$ & $(0.012)$ & $8.572^{\star \star \star}$ & $(0.016)$ \\
\hline 2006 & $9.305^{\star \star \star}$ & $(0.021)$ & $8.609^{\star \star \star}$ & $(0.012)$ & $8.615^{\star \star \star}$ & $(0.024)$ \\
\hline 2007 & $9.309^{\star \star \star}$ & $(0.021)$ & $8.588^{\star \star \star}$ & $(0.016)$ & $8.663^{\star \star \star}$ & $(0.018)$ \\
\hline 2008 & $9.290^{\star \star *}$ & $(0.027)$ & $8.606^{\star \star \star}$ & $(0.019)$ & $8.690^{\star \star \star}$ & $(0.019)$ \\
\hline 2009 & $9.317^{\star \star \star}$ & $(0.000)$ & $8.610^{\star \star \star}$ & $(0.000)$ & $8.671^{\star \star \star}$ & $(0.000)$ \\
\hline
\end{tabular}

\section{Grupo de idade}

20 a 25 anos (referência)

31 a 35 anos

$0.187^{* \star *} \quad(0.000)$

$0.164^{\star * *} \quad(0.000)$

$0.164^{\star * *}$

$(0.000)$

36 a 40 anos

$0.285^{\star \star *} \quad(0.000)$

$0.297^{\star \star *} \quad(0.000)$

$0.331^{\star * *} \quad(0.000)$

41 a 45 anos

$0.365^{\star \star *} \quad(0.019)$

$0.387^{\star \star \star} \quad(0.011)$

$0.420^{* * *} \quad(0.020)$

46 a 50 anos

$0.403^{* * *} \quad(0.029)$

$0.410^{\star \star \star} \quad(0.015)$

$0.409^{* * *}$

51 a 55 anos

$0.477^{\star \star \star} \quad(0.019)$

$0.461^{\star \star \star} \quad(0.018)$

$0.460^{\star \star \star} \quad(0.020)$

\begin{tabular}{lccc} 
Número de observações & 96 & 96 & 96 \\
$\mathrm{R}^{2}$ & 1 & 1 & 1 \\
\hline
\end{tabular}

* Estatisticamente significativo a 10\% de confiança; ${ }^{* *}$ a $5 \%$ de confiança, ${ }^{* * *}$ a $1 \%$ de confiança (testes bicaudais). Desvios padrão em parênteses. 
Tabela A.4 - Terceira etapa: todos os coeficientes da estimação dos diferenciais de salários por grupo de idade e ano entre trabalhadores qualificados e trabalhadores de baixa qualificação (Equação 16)

\begin{tabular}{|c|c|c|}
\hline Constante - Diferencial entre Qualificados e Não Qualificados & $0.826^{\star \star \star}$ & $(0.217)$ \\
\hline 20 a 25 anos (referência) & - & - \\
\hline 31 a 35 anos & 0.037 & $(0.044)$ \\
\hline 36 a 40 anos & 0.005 & $(0.050)$ \\
\hline 41 a 45 anos & -0.038 & $(0.050)$ \\
\hline 46 a 50 anos & -0.058 & $(0.046)$ \\
\hline 51 a 55 anos & -0.069 & $(0.049)$ \\
\hline Diferencial entre Qualificados e Intermediários & $-0.765^{\star \star \star}$ & $(0.039)$ \\
\hline 20 a 25 anos (referência) & - & - \\
\hline 31 a 35 anos & -0.016 & $(0.043)$ \\
\hline 36 a 40 anos & -0.020 & $(0.048)$ \\
\hline 41 a 45 anos & 0.014 & $(0.047)$ \\
\hline 46 a 50 anos & 0.049 & $(0.057)$ \\
\hline 51 a 55 anos & 0.083 & $(0.068)$ \\
\hline Tendência de demanda por trabalho qualificado & $0.012^{\star \star \star}$ & $(0.002)$ \\
\hline \multicolumn{3}{|l|}{ Coeficientes do Diferencial de Oferta } \\
\hline Entre grupos de idade $-1 / \sigma_{A}$ & $-0.097^{\star}$ & $(0.052)$ \\
\hline $\begin{array}{l}\text { Entre grupos de educação } \\
\text { (intermediários - não qualificados) }-1 / \sigma_{U}\end{array}$ & $-0.107^{\star \star \star}$ & $(0.031)$ \\
\hline $\begin{array}{l}\text { Entre grupos de educação } \\
\text { [qualificados - (intermediários e não qualificados)] }-1 / \sigma_{E}\end{array}$ & $-0.294^{\star \star \star}$ & $(0.052)$ \\
\hline Número de observações & 192 & \\
\hline $\mathrm{R}^{2}$ & 0,96 & \\
\hline
\end{tabular}

${ }^{*}$ Estatisticamente significativo a $10 \%$ de confiança; ${ }^{* *}$ a $5 \%$ de confiança, ${ }^{* * *}$ a $1 \%$ de confiança (testes bicaudais). Desvios padrão em parênteses. 
Tabela A.5 - Terceira etapa: todos os coeficientes da estimação dos diferenciais de salários por grupo de idade e ano entre trabalhadores qualificados e trabalhadores de baixa qualificação, com tendência quadrática

\begin{tabular}{|c|c|c|}
\hline Constante - Diferencial entre Qualificados e Não Qualificados & $0.826^{\star \star \star}$ & $(0.217)$ \\
\hline 20 a 25 anos (referência) & - & - \\
\hline 31 a 35 anos & 0.035 & $(0.042)$ \\
\hline 36 a 40 anos & 0.004 & $(0.046)$ \\
\hline 41 a 45 anos & -0.038 & $(0.050)$ \\
\hline 46 a 50 anos & -0.059 & $(0.048)$ \\
\hline 51 a 55 anos & -0.069 & $(0.051)$ \\
\hline Diferencial entre Qualificados e Intermediários & $-0.763^{\star \star *}$ & $(0.036)$ \\
\hline 20 a 25 anos (referência) & - & - \\
\hline 31 a 35 anos & -0.016 & $(0.039)$ \\
\hline 36 a 40 anos & -0.020 & $(0.042)$ \\
\hline 41 a 45 anos & 0.012 & $(0.044)$ \\
\hline 46 a 50 anos & 0.046 & $(0.051)$ \\
\hline 51 a 55 anos & 0.080 & $(0.060)$ \\
\hline Tendência Linear & $0.033^{\star \star \star}$ & $(0.004)$ \\
\hline Tendência Quadrática & $-0.014^{\star \star *}$ & $(0.001)$ \\
\hline \multicolumn{3}{|l|}{ Coeficientes do Diferencial de Oferta } \\
\hline Entre grupos de idade $-1 / \sigma_{A}$ & $-0.094^{*}$ & $(0.042)$ \\
\hline $\begin{array}{l}\text { Entre grupos de educação } \\
\text { (intermediários - não qualificados) }-1 / \sigma_{U}\end{array}$ & $-0.106^{\star \star}$ & $(0.026)$ \\
\hline $\begin{array}{l}\text { Entre grupos de educação } \\
\text { [qualificados - (intermediários e não qualificados)] }-1 / \sigma_{E}\end{array}$ & $-0.138^{\star \star \star}$ & $(0.084)$ \\
\hline Número de observações & 192 & \\
\hline $\mathrm{R}^{2}$ & 0,97 & \\
\hline
\end{tabular}

${ }^{*}$ Estatisticamente significativo a $10 \%$ de confiança; ${ }^{* *}$ a $5 \%$ de confiança, ${ }^{* * *}$ a $1 \%$ de confiança (testes bicaudais). Desvios padrão em parênteses.

A Tabela A.5 a seguir apresenta os resultados da última etapa de estimação - referente à Equação (16) - porém sem estimar novamente as elasticidades de substituição entre grupos etários $\left(\sigma_{A}\right)$ e entre trabalhadores de baixa qualificação $\left(\sigma_{U}\right)$. Corrigimos os salários pelas diferenças de oferta nos grupo de idade e dos trabalhadores de baixa qualificação. 
Ou seja, passamos os termos referentes a essas duas medidas de oferta para o lado esquerdo da Equação (16) e re-estimamos novamente o modelo, de acordo com a seguinte equação:

$$
\begin{gathered}
w_{3 a t}-w_{e a t}+1 / \sigma_{u}\left(n_{U a t}-n_{e a t}\right)+1 / \sigma_{A}\left[\left(n_{U t}-n_{U a t}\right)-\left(n_{3 t}-n_{3 a t}\right)\right] \\
=f_{0}^{\prime}-f_{1} t+d_{e a}-1 / \sigma_{E}\left(n_{3 t}-n_{U t}\right) \\
\mathrm{e}=1,2
\end{gathered}
$$

Tabela A.5 - Terceira etapa: estimação dos diferenciais de salários (corrigidos por diferenças de oferta nos grupo de idade e de trabalhadores de

\begin{tabular}{|c|c|c|}
\hline Diferencial entre Qualificados e Não Qualificados & 0.822 & $(0.031)$ \\
\hline 20 a 25 anos (referência) & - & - \\
\hline 31 a 35 anos & 0.039 & $(0.031)$ \\
\hline 36 a 40 anos & 0.008 & $(0.031)$ \\
\hline 41 a 45 anos & -0.035 & $(0.033)$ \\
\hline 46 a 50 anos & $-0.055^{\star \star}$ & $(0.026)$ \\
\hline 51 a 55 anos & $-0.066^{* *}$ & $(0.026)$ \\
\hline Diferencial entre Qualificados e Intermediários & $-0.764^{\star \star \star}$ & $(0.028)$ \\
\hline 20 a 25 anos (referência) & - & - \\
\hline 31 a 35 anos & -0.016 & $(0.041)$ \\
\hline 36 a 40 anos & -0.020 & $(0.041)$ \\
\hline 41 a 45 anos & 0.013 & $(0.042)$ \\
\hline 46 a 50 anos & 0.048 & $(0.038)$ \\
\hline 51 a 55 anos & $0.082^{\star *}$ & $(0.038)$ \\
\hline Tendência de demanda por trabalho qualificado & $0.012^{* \star *}$ & $(0.002)$ \\
\hline \multicolumn{3}{|l|}{ Coeficientes do Diferencial de Oferta } \\
\hline $\begin{array}{l}\text { Entre os grupos de idade } \\
\text { Entre grupos de educação } \\
\text { [qualificados - (intermediários e não qualificados)] }\end{array}$ & $-0.295^{\star \star *}$ & $(0.078)$ \\
\hline Número de observações & 192 & \\
\hline $\mathrm{R}^{2}$ & 0,96 & \\
\hline
\end{tabular}
baixa qualificação) entre trabalhadores qualificados e trabalhadores de baixa qualificação

${ }^{*}$ Estatisticamente significativo a $10 \%$ de confiança; ${ }^{* *}$ a $5 \%$ de confiança, ${ }^{* * *}$ a $1 \%$ de confiança (testes bicaudais). Desvios padrão em parênteses. 


\section{Apêndice B - Resultados com Diferentes Medidas de Oferta}

Tabela B.1 - Primeira etapa: estimação dos diferenciais de salários por grupo de idade e ano entre trabalhadores intermediários e não qualificados

\begin{tabular}{ccccc}
\hline Expomos apenas os coeficientes do termo de oferta da Equação (11) Nessa etapa $\sigma_{u}$ é identificado. & \\
\hline & $(1)$ & $(2)$ & $(3)$ & $(4)$ \\
$-1 / \sigma_{U}$ & $-0.107^{\star \star \star}$ & $-0.115^{\star \star \star}$ & $-0.139^{\star \star \star}$ & $-0.149^{\star \star \star}$ \\
Número de observações & $(0.030)$ & $(0.031)$ & $(0.014)$ & $(0.016)$ \\
$\mathrm{R}^{2}$ & 96 & 96 & 96 & 96 \\
\hline
\end{tabular}

* Estatisticamente significativo a $10 \%$ de confiança; ${ }^{* *}$ a $5 \%$ de confiança, ${ }^{* * *}$ a $1 \%$ de confiança (testes bicaudais). Desvios padrão em parênteses.

(1) Medida de oferta: Horas de trabalho

(2) Medida de oferta: Trabalhadores

(3) Medida de oferta: PEA

(4) Medida de oferta: População Total

Tabela B.2 - Segunda etapa: estimação dos diferenciais de salários por grupo de idade e ano entre trabalhadores qualificados e trabalhadores de baixa qualificação

Expomos apenas os coeficientes dos termos de oferta da Equação (12)

Nessa etapa $\sigma_{A}$ é identificado e temos uma nova estimativa para $\sigma_{u}$.

(2)

(3)

$$
\begin{aligned}
& -1 / \sigma_{U} \\
& -1 / \sigma_{A}
\end{aligned}
$$

$-0.107^{\star \star \star}$

$-0.114^{\star * *}$

$-0.144^{\star \star \star}$

(0.020)

$-0.154^{\star \star *}$

$-0.099^{* *}$

(0.030)

$(0.044)$

$-0.122^{* *}$

$-0.082^{*}$

$-0.087^{\star *}$

Número de observações

96

96

(0.050)

(0.051)

$\mathrm{R}^{2}$

0.98

0.99

96

96

0.99

* Estatisticamente significativo a 10\% de confiança; **a 5\% de confiança, ***a 1\% de confiança (testes bicaudais). Desvios padrão em parênteses.

(1) Medida de oferta: Horas de trabalho

(2) Medida de oferta: Trabalhadores

(3) Medida de oferta: PEA

(4) Medida de oferta: População Total 
Tabela B.3 - Terceira etapa: estimação dos diferenciais de salários por grupo de idade e ano entre trabalhadores qualificados e trabalhadores de baixa qualificação

\begin{tabular}{|c|c|c|c|c|}
\hline \multicolumn{5}{|c|}{$\begin{array}{l}\text { Expomos apenas os coeficientes da demanda e dos termos de oferta da Equação (16). } \\
\text { Nessa etapa a tendência de demanda e } \sigma_{E} \text { são identificados, e temos novas estimativas para } \sigma_{A} \text { e } \sigma_{u} \text {. }\end{array}$} \\
\hline & (1) & (2) & (3) & (4) \\
\hline Tendência de demanda por trabalho qualificado & $\begin{array}{c}0.012^{\star \star *} \\
(0.002)\end{array}$ & $\begin{array}{c}0.013^{\star \star *} \\
(0.002)\end{array}$ & $\begin{array}{c}0.012^{\star \star *} \\
(0.001)\end{array}$ & $\begin{array}{c}0.006^{\star \star *} \\
(0.001)\end{array}$ \\
\hline$-1 / \sigma_{E}$ & $\begin{array}{c}-0.294^{\star \star \star} \\
(0.082)\end{array}$ & $\begin{array}{c}-0.377^{\star \star \star} \\
(0.088)\end{array}$ & $\begin{array}{c}-0.636^{\star * \star} \\
(0.097)\end{array}$ & $\begin{array}{c}-0.440^{\star \star \star} \\
(0.069)\end{array}$ \\
\hline$-1 / \sigma_{A}$ & $\begin{array}{l}-0.097^{\star} \\
(0.051)\end{array}$ & $\begin{array}{c}-0.120^{\star *} \\
(0.057)\end{array}$ & $\begin{array}{l}-0.096^{\star} \\
(0.054)\end{array}$ & $\begin{array}{c}-0.102^{\star * \star} \\
(0.056)\end{array}$ \\
\hline$-1 / \sigma_{U}$ & $\begin{array}{c}-0.107^{\star \star \star} \\
(0.031)\end{array}$ & $\begin{array}{l}-0.114^{\star \star \star} \\
(0.033)\end{array}$ & $\begin{array}{l}-0.147^{\star * *} \\
(0.021)\end{array}$ & $\begin{array}{l}-0.157^{\star \star \star} \\
(0.024)\end{array}$ \\
\hline Número de observações & 192 & 192 & 192 & 192 \\
\hline $\mathrm{R}^{2}$ & 0,96 & 0,96 & 0,97 & 0,97 \\
\hline
\end{tabular}

${ }^{*}$ Estatisticamente significativo a $10 \%$ de confiança; ${ }^{* *}$ a $5 \%$ de confiança, ${ }^{* * *}$ a $1 \%$ de confiança (testes bicaudais).

(1) Medida de oferta: Horas de trabalho. Desvios padrão em parênteses.

(2) Medida de oferta: Trabalhadores

(3) Medida de oferta: PEA

(4) Medida de oferta: População Total

\section{Apêndice C - Salários por Grupo de Idade}
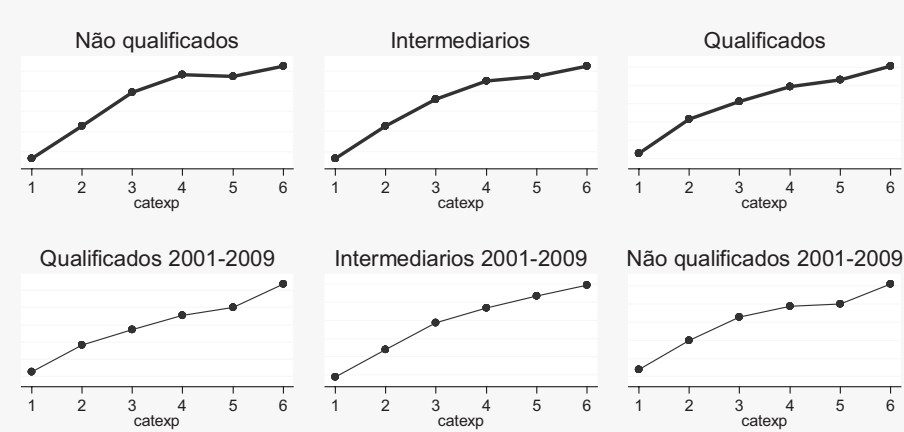

Não qualificados 2001-2009
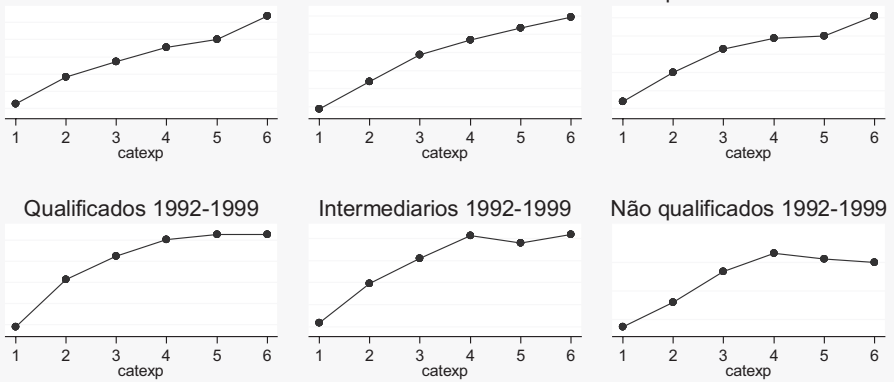

Não qualificados 1992-1999

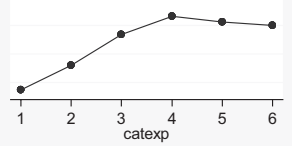

Gráfico C.1 - Média dos salários observados por grupo etário. 1992 - 2009

Fonte: Cálculos próprios a partir dos dados das PNADS 1992 a 2009.

Nota: O gráfico expõe, para cada um dos três grupos de qualificação, a média dos salários observados por grupo de idade. Fazemos isso para todo período de observação e também dividimos a nossa amostra em dois períodos: 1992 a 1999 e 2001 a 2009. 
Analisando os salários médios para todo o período de observação (três gráficos superiores), percebe-se que o salário médio aumenta à medida que o grupo de idade é maior ( 1 refere-se ao grupo mais jovem, 26 a 30 anos, e 6 ao mais velho, 51 a 55 anos). Porém, ele aumenta em uma proporção decrescente, representando função côncava para a curva de salários por grupo de idade. Ou seja, o salário se eleva com uma maior idade, mas esse acréscimo é cada vez menor.

Quando analisamos separadamente a década de 1990 e 2000, vemos um padrão diferente. $\mathrm{Na}$ década de 1990, a concavidade da curva de salários por grupo etário é maior no caso dos indivíduos qualificados. Já para os intermediários e não qualificados, os salários médios referentes aos maiores grupos etários (5 e 6) inclusive passam a decrescer. Esse comportamento muda a partir de 2001; a curva de salários por grupo etário passa a ter uma forma mais linear. Esse fato indica que trabalhadores com maior idade (46 a 55 anos) passaram a ser mais valorizados no mercado de trabalho brasileiro durante a década de 2000. 